For bark and pith anatomy a new set of character states and definitions is proposed. It will be interesting to test the bark features in the forthcoming meeting of the IAWA Committee on Bark Terminology. It may well be that some features now codified are transient character states in the secondary phloem of the young, developing twigs studied here.

As a philosophical afterthought, we perhaps need to re-open the debate on standardisation of terminology 50 years after the publication of IAWA's Multilingual Glossary of Terms (IAWA Committee 1964), 25 years following the publication of the IAWA List of Microscopic features for Hardwood Identification (IAWA Committee1989), 10 years after the emergence of its Softwood companion (IAWA Committee 2004), and in the current early phase of the IAWA Committee on Bark Anatomical Terms (2014/2015). The Schweingruber school trains more young plant anatomists during the popular summer schools than most other centres, and it is vital that our terminologies remain unified and unambiguous for generations to come.

Never mind these considerations, this Atlas is an extremely valuable addition to our knowledge on stem anatomical diversity in Mediterranean plants, and the authors are to be congratulated with its publication.

Pieter Baas

Wood properties of the global important tree species. Jiang Zehui (chief editor), xiii + 521 pp., illus., 2013. Science Press Beijing, China. ISBN 978-7-03-038738-7. Price RMB 220 / USD 95 (hard cover).

Just in time for presentation at the successful 8th Pacific Regional Wood Anatomy Conference in Nanjing last October, this updated and expanded English version of a compendium on Worldwoods that was first published in Chinese in 2001 is a very welcome addition to the literature on commercial timbers. It covers not less than 84 softwood species and 374 hardwood species, treated by geographical provenance: China (86 spp.), SE Asia and Pacific (133 spp.), Tropical America (75 spp.), Tropical Africa (63 spp.), Europe (51 spp.) and North America (50 spp.). For each species wood anatomical micrographs of transverse, tangential, and radial sections illustrate texts with information on common names, tree description and distribution, wood characteristics, wood anatomical features, wood properties and wood uses. The quality of the descriptions and illustrations is usually very good. The only weaknesses are some linguistic slips introduced in translation and the inclusion of a few images of some poor sections with broken vessel walls.

Although initially the Chinese version must have based its species selection on timbers available on the Chinese import market, the global relevance of this book is evident as it illustrates and gives attributes of commercial species that are not often included in other timber handbooks, and are based on specimens from Chinese collections that may deviate in properties of those tested for other manuals. The editor and numerous contributors are to be congratulated on making this important source of information now internationally available.

Pieter Baas

Anatomía de Maderas en Comunidades Rurales de Yucatán (in Spanish with English summary). Fidel A. Roig Juñent, José Villanueva Díaz, Juan J. Jiménez Osornio, W. John Hayden, Joséfina Barajas Morales \& Brian H. Luckman, xii + 242 pp., colour illus., 2012. INIFAP, Mexico, ISBN 978-607-425-900-1. Book copies for libraries or laboratories are free of charge (except postage) on request from INIFAP (send mail to: José Villanueva Díaz (villanueva.jose@inifap.gob.mx). 
This is a delightful atlas of 48 useful timbers from the Yucatán Peninsula in México. Useful not only for modern use, but also for the rich and ancient Maya culture which strongly influenced tree species composition in this region. In the introductory chapters the geomorphology, climate, forests, home gardens (Solares), and tree growth patterns in Yucatán are introduced. The main body of the book consists of 48 species treatments of four pages, each containing information on the etymology, Maya names, tree attributes, distribution and ecology, uses and finally and most importantly the wood anatomy and growth ring characteristics. Each species is illustrated with colour pictures of both its reproductive and vegetative macromorphology and with macro- and micrographs of finely polished end grain surfaces at different magnifications. The very high quality of the polished surfaces is evident from the exquisite high magnification micrographs, that are as good as images of perfect microtome sections.

Since one of the major goals for this book was to study the potential of Yucatán timbers for growth periodicity and dendroclimatological research, the wood anatomical descriptions focus on the nature of the growth ring boundaries, which are distinct in $38 \%$, and of varying distinctness in another $20 \%$ of the species, doubtlessly due to the prolongued dry seasons in this hot tropical peninsula. The vast majority of the species is diffuse porous, but a few deciduous species are ring-porous or semi-ring-porous. When distinct, most growth rings are marked by marginal parenchyma.

Based on this first selection, the authors give some useful suggestions for future studies of species with a high potential for tree growth and dendroclimatological studies. The book is a warmly recommended addition to the literature on tropical timbers and their growth periodicity.

Pieter Baas

\section{ACKNOWLEDGEMENT OF REVIEWERS}

The editors and associate editors wish to thank the following colleagues for reviewing manuscripts submitted to the IAWA Journal in 2013.

Hisashi Abe
Stergios Adamopoulos
Susan A. Anagnost
Guillermo Angeles
Pieter Baas
Claudia Baitinger
Marion Bamford
John Barnett
Giovanna Battipaglia
Hans Beeckman
Kevin Boyce
Bruno Clair
David Collings
Dave Cowan
Geoffrey Daniel
Dario De Franceschi
Veronica De Micco
Alan Dickson
Lloyd A. Donaldson
Oliver Dünisch

$\begin{array}{ll}\text { Roland Dute } & \text { Frederic Lens } \\ \text { Dieter Eckstein } & \text { Simcha Lev-Yadun } \\ \text { Luis Garcia Esteban } & \text { Eryuan Liang } \\ \text { Robert Evans } & \text { Emanuele Lingua } \\ \text { Frank Ewers } & \text { Katri Luostarinen } \\ \text { Esther Fichtler } & \text { Carmen Marcati } \\ \text { Tomoyuki Fujii } & \text { Regis B. Miller } \\ \text { Peter Gasson } & \text { George Edward Mustoe } \\ \text { Carole Gee } & \text { Shuichi Noshiro } \\ \text { Uwe Hacke } & \text { Jorg Olivar } \\ \text { Roger Hernandez } & \text { Alexei Oskolski } \\ \text { Jugo Ilic } & \text { Marcelo Pace } \\ \text { Takaoh Itoh } & \text { Jorge Paiva } \\ \text { Bonnie Jacobs } & \text { Marc Philippe } \\ \text { Steven Jansen } & \text { Kathleen Pigg } \\ \text { Peter Kitin } & \text { Gianluca Piovesan } \\ \text { Gerald Koch } & \text { Imogen Poole } \\ \text { Keiko Kuroda } & \text { Peter Prislan } \\ \text { Dai Kusomoto } & \text { Fidel Roig } \\ \text { Barbara Lachenbruch } & \text { Jakub Sakala } \\ & \end{array}$

\author{
Ute Sass \\ Laurie R. Schimleck \\ Uwe Schmitt \\ Nele Schmitz \\ Julia Sonsin \\ Rachel Spicer \\ Keiji Takabe \\ Edith Taylor \\ Kazuo Terada \\ Teresa Terrazas \\ Romain Thomas \\ Roberto Tognetti \\ Vaclav Treml \\ Iris Vasquez \\ Georg Von Arx \\ Elisabeth Wheeler \\ Alex A.Wiedenhoeft \\ Michael C.Wiemann \\ Fukuju Yamamoto \\ Audrey Zink-Sharp
}

